\title{
EN BUSCA DEL MECENAZGO REAL: AUTORAS ROMÁNTICAS Y PALACIO
}

\author{
$\mathrm{M}^{\mathrm{a}}$ del Carmen SimÓN PALMER \\ Consejo Superior de Investigaciones Científicas
}

\section{RESUMEN}

La Real Biblioteca conserva un elevado número de manuscritos de autoras que buscaron la protección de las reinas, especialmente de Isabel II, por medio de poesías a ellas dedicadas. Unas veces a título individual y otras como parte de obras colectivas, los temas de que tratan se refieren a las actividades derivadas de su papel real: viajes, la inauguración del Canal de su nombre, la cesión de su bienes en 1856 y en muchos casos biográficas. Por último dos cartas autógrafas de Gertrudis Gómez de Avellaneda al duque de Riansares sobre su pretensión, no conseguida, de entrar en Palacio como dama de la reina.

Palabras clave: Escritoras. Manuscritos inéditos. Poesías laudatorias. Francisca Carlota del Riego Pica. Faustina Sáez de Melgar. Gertrudis Gómez de Avellaneda.

\section{ABSTRACT}

The Royal Library holds a number of manuscripts written by female authors who attempted to gain the protection and favor of the queens, particularly with Queen Isabel II, dedicating poems to her. At times, an individual publication, as well as other collective works became themes that focused on her real life contributions: her travels, the inauguration of a Canal with her name, Canal Isabel II, donations of her goods in 1856, as well as several other cases in her biography. Lastly, there are two letters written by Gertrudis Gómez de Avellaneda to the Duke of Riansares speaking about an unfulfilled desire of entering the Royal Palace by becoming a lady-in-waiting for the Queen.

Keywords:Writers. Unpublished Manuscripts. Laudatory poems. Francisca Carlota del Riego Pica. Faustina Sáez de Melgar. Gertrudis Gómez de Avellaneda. 
Es conocido que los autores del Siglo de Oro dedicaron de manera habitual sus obras a grandes señores y a los monarcas, pero creemos que hasta el momento no se ha reparado en que las escritoras hicieron otro tanto. En el periodo que nos ocupa, cuando la mujer sale del espacio cerrado y participa en la vida pública, son diversas las motivaciones y los pretextos que les llevan a dirigirse a las personas reales, y más concretamente a la reina. La mayoría de las veces le dedican poemas panegíricos, pero tampoco falta alguna petición de trabajo o de ayuda, casi siempre a través de intermediarios.

Ya en los últimos años del siglo XVIII, varias aristócratas desde su puesto como directivas en la Real Sociedad Económica de Amigos del País, aprovechan la entrega de premios a los alumnos, acto al que solía acudir la reina, para ofrecerle sus discursos. Aparecen los nombres de Magdalena Fernández Ponce de León, hija del Marques de Castromonte que, junto a su marido, hace un elogio de la Sra. Infanta Doña María Ana Victoria, cuando ésta ya ha fallecido $^{1}$; también la marquesa de Ariza, doña Joaquina Fernández de Córdoba, que lee un elogio a la Reina el 21 de enero de 1795² la Marquesa de FuerteHijar, que hace otro tanto en el mismo acto el año $1798^{3}$ o Josepha Diez de la Cortina y de Morales, el 18 de diciembre de $1799^{4}$.

La Junta de Señoras, una de las numerosas sociedades femeninas, ya en 1819 dedica un elogio a la Reina María Isabel de Braganza, esposa de Fernando VII, que es leído en virtud de acuerdo de la Junta por la Marquesa de Villafranca, Duquesa de Medina-Sidonia, en la sesión celebrada el 17 de Febrero ${ }^{5}$.

\section{REINADO DE ISABEL II}

El modo más eficaz para conseguir lectores y asegurar la continuidad de una publicación periódica dedicada al público femenino, era conseguir que la Reina figurase al frente de la lista de suscriptores.

Es sorprendente el elevado número de autoras que consagran sus poemas a Isabel II, la mayoría de las veces a título individual y otras como participantes en obras colectivas. Era esta reina aún pequeña cuando Juana Vega se encarga de su educación y el contacto con esta mujer inteligente, que conocía

1. Publicada por Joseph Banquieri en el Diario de Madrid de 26/IX/1789. Había fallecido en 1781 y estuvo casada con el rey de Portugal.

2. Madrid, Imprenta de Sancha, [s.a. 1795], 2, XIII pp.

3. Madrid, Imprenta de Sancha, 1798, 18 pp.

4. Madrid, Imprenta Real por don Pedro Pereyra, impresor de Cámara de S.M., 1800, 32 pp.

5. Madrid, Imprenta de Repullés, 1819, 15 pp.

Anales, 23, 2011, pp. 289-308 
varios idiomas y que escribirá luego su biografía y las memorias de su marido, el general Espoz y Mina, influyó en las relaciones posteriores de su pupila con el mundo femenino, de forma que en su madurez las escasas amigas no responderán al modelo habitual de damas de Corte. Una de éstas, María de los Dolores Quiroga, Sor Patrocinio, fue un personaje controvertido, de cuya obra la Real Biblioteca guarda un ejemplar y menciones en cartas cruzadas entre las infantas, ya en los años 70 .

La otra amiga es la Vizcondesa de Jorbalán, Micaela Desmasiéres, santificada como Santa Micaela del Santísimo Sacramento, fundadora de las Adoratrices que se consagran a la protección de prostitutas y mujeres en peligro, amiga a su vez de la duquesa de Mina. Por encargo del confesor de la Reina, Antonio María Claret, la Vizcondesa va a acompañarla tras sus numerosos partos.

Asimismo en las audiencia reales no faltan los nombres de autoras que desean entregarle manuscritos a ella dedicados, como Robustiana Armiño ${ }^{6}$, Narcisa Pérez de Reoyo ${ }^{7}$ (1867) o Antonia Díaz de Lamarque $^{8}$ (s.a. 1862), y son recompensadas por Isabel II con valiosos regalos.

A continuación damos noticia de los manuscritos que se conservan en la Real Biblioteca, muchos de ellos inéditos y algunos de autoras desconocidas hasta el momento.

\section{MOTIVOS}

\section{LA REINA}

En 1846, Gertrudis Gómez de Avellaneda publica en el Álbum literario español un poema «A S.M. la Reina doña Isabel II», que comienza: [ «Cuando al imperio de su voz rugiente...» $]^{9} ;$ y cuyo manuscrito original, fechado el año 1843, titula «Oda» en el Album de S.M. Isabel II, con colaboraciones de Rodríguez Rubí, L. Augusto del Cueto, o el Duque de Rivas, entre otros, y de Josefa Massanés con un «Poema» [«Cuando tras lucha aciaga y fratricida...»] ${ }^{10}$.

Recurso fácil y halagador es el símil que establecen con su antepasada homónima: Isabel la Católica. Así, Rosa Amparo de Montenegro alude a la

6. ARmiño Cuesta, Robustiana, Flores del Paraíso o Ilustración de la Infancia. Gijón. Imp. y Libr. de D.L. González. 1852, XVI, 254 pp.

7. PÉREz Reoyo, Narcisa. Devocionario infantil en verso, Lugo, Imp. de Soto Freire, 1867, 4 h, 192 pp.

8. Díaz de Lamarque, Antonia, A S. M. la Reina doña Isabel II en su visita al Hospital de la Santa Caridad, Sevilla [s.n],[s.a. 1862], 1 h.

9. Madrid, Tip. Francisco de Paula Mellado, 1846, pp. 259-265.

10. Album de S.M. Isabel II,1843, fol. 19v-20r, Real Biblioteca, Mss II/ 3290.

Anales, 23, 2011, pp. 289-308 
grandeza que invoca y al descubrimiento de América, para concluir con la certeza de que la época de Isabel II será similar.

A mi Reina y Señora ${ }^{11}$

Nombrad al Sol, y al punto la belleza

de su radiante faz llena la mente:

nombrad la rosa, y brota de repente

la idea de su aroma y gentileza.

Así del nombre de Isabel grandeza

destella en lo pasado y lo presente

del pueblo mas altivo de Occidente,

que inclina al pronunciarlo su cabeza.

Si en lo pasado de Colón la gloria

solo Isabel primera es quien la funda,

de lo presente ya dirá la Historia:

«La era para España mas fecunda

en lauros dignos de eternal memoria,

comprendía un nombre, el de Isabel segunda».

María Mendoza de Vives, es autora del poema «A S.M. la Reyna D ${ }^{a}$ Ysabel II» [«Yo ansiaba conocerte; el eco inmenso...»] ${ }^{12}$.

\section{NACIMIENTOS Y MUERTES DE LOS HIJOS DE ISABEL II}

Los doce partos de Isabel II dieron motivo para muchos poemas. María Dolores Cabrera y Heredia publica el 12 de julio de 1850, al fallecer el Príncipe Luis de Borbón y Borbón: A S.M. el Rey en la muerte de su inocente y augusto hijo el Príncipe de Asturias: poesía ${ }^{13}$. Años más tarde los Reyes serían sus padrinos de boda.

No sabemos la fecha exacta ni, en consecuencia, a qué nacimiento se refiere María Juana Quintano y Medina en su: Canto, plegaria y soneto en acción de gracias... por el feliz alumbramiento de S.M... Isabel $\mathrm{II}^{14}$, que no está dedicado al futuro Alfonso XII porque ya entonces había cesado su actividad el impresor de esta obra. Cecilia Bohl de Faber, como Fernán Caballero, publica unos Recuerdos de la Infanta Doña María de Regla de Orleans y Borbón, que vino al mundo el 8 de Octubre de 1856 y subió al Cielo el 25 de Julio de $1861^{15}$.

11. Real Biblioteca, Mss II/4040 (10), 1 hoja de papel labrado en los bordes. Autógrafo firmado.

12. Real Biblioteca, Mss VIII/M/262, f. 69r-70r. Autógrafo a dos columnas.

13. [Madrid:s n. 1850], 2 pp.

14. [Madrid: s.n., entre 1848 y 1856], (Imp. de J.M. Alonso), 4 hs.

15. Sevilla: [S.n.], 1861 (F. Alvarez y C ${ }^{a}$, Impresores), 57 pp. Con un retrato de Doña María de la Regla. 
En la Corona poética a Isabel II, Ángela Grassi también dedica un poema Al feliz alumbramiento de S.M. 1851 [«Reina, sois muy feliz! Teneis ahora...»] ${ }^{16}$.

\section{ALFONSO XII, PRÍNCIPE}

El 28 de noviembre de 1857 nace el futuro Alfonso XII y se convierte en destinatario de un sinnúmero de poemas. Se conserva el manuscrito autógrafo de Gertrudis Gómez de Avellaneda titulado Alfonso el Sabio, romance en el que se remonta a Augusto para hablar de Alfonso el Sabio y aludir así al príncipe heredero. Son muchas las variantes entre el original y la versión publicada [ Del grande imperio de Augusto...»] ${ }^{17}$. Ya antes había escrito una Oda. Al fausto natalicio de S.A.R. El Sermo. Señor Príncipe de Asturias [ « ¿Por qué la paz de la tranquila noche...»] ${ }^{18}$.

Como «una autora aficionada», se define Josefa del Real de Rosado, de la que no teníamos noticia, que compone una Improvisación que una aficionada y amante fiel de su idolatrada Reina Doña Isabel Segunda en el mismo día que supo el nacimiento feliz de S.A.R. Srmo Sr. Principe de Asturias ${ }^{19}$.

¡Feliz ya la España, enjuga tu llanto que propicio el Cielo Príncipe te ha dado! Unamos los votos ardientes y santos, y al Cielo las gracias juntos se las damos.

Cantemos victoria y el Pendon alzando sobre los blasones del Rey don Pelayo, ¡El Principe viva! y mas confiado,

16. Ovilo y OTERO, Manuel. Corona poética ofrecida á SS.MM. la Reina Doña Isabel II y el Rey Don Francisco de Asis Maria, con motivo del nacimiento de su Augusta hija S.A.R. la Serma. Sra. Princesa Doña Maria Isabel Francisca de Borbón, en nombre de los poetas españoles. Madrid, (Imp. de Operarios á cargo de D. Francisco R. del Castillo), 1851.

17. Real Biblioteca, Mss II/4040 (2), 9 hs por ambas caras, autógrafo firmado. Impreso en Obras Literarias. I. Poesías líricas, Madrid, Libr. Leocadio López, 1877, p. 284.

18. Real Biblioteca, Mss II/4040 (33), 5 hs. autógrafas.

19. Real Biblioteca, Mss II/4040 (34), 1 h. autógrafa a tres columnas escrita a lápiz con bonita letra y fechada el 28-XI-1857. 
que España lo ama

por Rey deseado.

$¡ \mathrm{O}$ augusta Reina

Ysabel amada!

De tu pueblo noble

eres aclamada.

Ese regio trono

que te fue heredado

de mas de cien Reyes,

custodiad y dadlo

al Regio Heredero

que el Cielo te ha dado:

Velad, Reina Augusta,

por sus dias largos

para ser la dicha

de su Reino amado.

Felices ya seremos, cesen nuestros llantos, discordias no hayan, que solo anhelamos, estar siempre unidos, valientes y bravos, entusiastas firmes del Príncipe amado.

$\mathrm{Y}$ a ti, augusto Padre, te felicitamos,

por la dicha grande

que a España le has dado.

Y gozad dichoso

de su amor y encantos,

con su augusta Madre

siempre custodiadlo.

El nacimiento del futuro Alfonso XII reunió también a colectivos de mujeres insospechados, que descubrieron sus facultades poéticas. Es el caso del Cuerpo de Coros de señoras del Teatro Real: A SS.MM. la Reina $D^{a}$ Isabel Segunda y su Augusto Esposo con motivo del natalicio del Príncipe de Asturias.

¡Madre feliz que escuchas cariñosa

del pueblo hispano el Santo regocijo;

Padre feliz que nos legaste un hijo

iris de paz de España venturosa!

Hoy ya la dicha por doquier rebosa

después de tanto padecer prolijo

y el pensamiento marcha siempre fijo

acariciando una ilusión hermosa. 
Y pues vemos brillar en lontananza

la estrella que entusiastas contemplamos, terror y espanto de traidores greyes(sic), renace en nuestros pechos la esperanza y con radiante júbilo esclamamos (sic)

¡Vivan de España los Augustos Reyes! ${ }^{20}$

La granadina Eduarda Moreno Morales de López-Nuño también celebró el acontecimiento con un poema: En el feliz natalicio de S.A.R. el príncipe de Asturias [ «Salud al noble niño...»] $]^{21}$.

Las felicitaciones se repitieron en los sucesivos aniversarios del príncipe heredero, como hace María Juana Quintano y Medina Al Augusto Príncipe de Asturias en el día de su Santo ${ }^{22}$, en 1864, con su [Poema] a S.A.R. el Serenísimo Señor Príncipe de Asturias [Alfonso XII] en su cumpleaños: [ ¡Dios de Israel, la España generosa...»] $]^{23}$, y Al Serenísimo Señor Príncipe de Asturias. Poema: [«De Dios las Supremas leyes...»] ${ }^{24}$.

No se olvidó en ese día a la madre, como hace Francisca Carlota del Riego Pica: A S.M. la Reina $D^{a}$ Isabel $2^{a}$. Con motivo del $7^{o}$ aniversario de su Augusto hijo el Serenisimo Sr. Príncipe de Asturias:

Cuando una reina como vos, Señora

rige de un pueblo noble los destinos

y acongojada con sus males llora

cumpliendo los divinos

Preceptos del Señor de las Alturas,

y premia al bueno,

y al valiente acorre (socorre)

y al infeliz ampara

se enagena los libres corazones

del pueblo que la admira

y la colma doquier, de bendiciones.

Y ahora vos Señora

que el cetro prepotente

de la nación más noble y generosa,

en vuestras manos ostentais clemente,

$\mathrm{y}$ adornais vuestra frente

con la doble corona

de reina augusta, y sin igual matrona

20. Real Biblioteca, Mss II/4040 (35). Un cartón muy bonito, orlado en colores, a mano. En la parte superior la imagen del Príncipe recién nacido.

21. Real Biblioteca, Mss 3525, fol. 6r-9r.

22. Madrid, Lit. Sancha [Ca.1860], Real Biblioteca, Caja/FollFol/135 (15).

23. Real Biblioteca, Mss II/1414 (2), autógrafo firmado.

24. Real Biblioteca, Mss II/1414 (18), autógrafo firmado.

Anales, 23, 2011, pp. 289-308 
(1v)Permitid que hasta vos, mi voz humilde se eleve en este dia que un reina que gime cuando su pueblo llora bien puede permitir, noble señora que su pueblo se asocie a su alegria y con afan prolijo las dulces bendiciones que agradecido de su pecho laura se desparramen tambien sobre tu hijo de mi patria querida la esperanza.

Yo pobre y humildosa no le puedo ofrecer ricas preseas ni joyas valiosas, hija soy de un soldado que en su defensa del trono su hacienda y su existencia ha prodigado, Mas si en defensa de tan caro objeto ha gastado su vida y su fortuna pobre viva señora, pero honrado, y a amaros me enseñó desde la cuna.

Por eso no vacilo en ofreceros las humildes preces de un corazón con vuestro amor nutrido, que si de tu grandeza

[2] pueden cegarme los fulgentes rayos, se que sobra a tu pecho la grandeza para amar el amor de tus vasayos, y que mas que preseas y blasones con sangre de tus hijos conquistados, anhelas cautivar los corazones. Si al pie del trono elevo reverente la sencilla espresión de mi cariño, al cielo en tanto rogaré ferviente proteja al tierno niño, al angel candoroso, a quien un dia llamará la historia Alfonso el Sabio, el grande, el bondadoso. ${ }^{25}$

25. Real Biblioteca, Mss II/4040 (92), autógrafo firmado. 


\section{LA ENTREGA DEL REAL PATRIMONIO}

El año 1865 se le pidió a la reina que renunciara a su Patrimonio para tratar de solucionar el estado de la Hacienda pública, pero se reservó una parte para los gastos de la Corona. Pronto surgieron los cortesanos elogiando la generosidad y, también críticas como la de Emilio Castelar, quien en su artículo «El rasgo», publicado el 22 de febrero en La Democracia, defendía que el Patrimonio Real era en realidad Patrimonio Nacional y combatía los empalagosos elogios al gesto de la reina, lo que acabó por costarle su cátedra de Historia en la Universidad Central.

Una de las panegiristas fue Carmen de Espejo y Valverde, que en su poema pasa de la gratitud a la comparación con las joyas que Isabel la Católica regaló a Colón, para acabar aludiendo al futuro monarca. Se publicó luego en Poesías dedicadas a Isabel II, el año $1865^{26}$, con variantes respecto al manuscrito: Oda. A S.M. la Reyna Doña Isabel Segunda ${ }^{27}$ : [ «Salud y bendición. Paz sobre Aquella...»] (Poesías: 229-231)

Robustiana Armiño de Cuesta, que un año antes había dedicado a Isabel II su obra El Ángel de los tristes, encabeza la versión impresa de estas Poesías (10-12), A S.M. la Reina: [ «Coronada de altisimas montañas...»] ${ }^{28}$, también en su caso el manuscrito contiene muchas variantes como fuentes por frentes, flamígeros por purísimos, magnífica espesura por grata espesura, etc., etc.

Varias autoras participaron en esta publicación, cuyo original conserva la Real Biblioteca: Francisca Carlota del Riego repite el objeto del homenaje en su título: A S.M. la Reina $D^{a}$ Isabel II. Por la magnánima acción de ceder sus bienes al Estado: [ «Veis en la selva umbría...»]; Faustina Saez de Melgar que le había dedicado en 1854 La lira del Tajo, también colabora en esta obra (Poesías: 34-36); Isabel Ocio y Sato, A S.M. la Reina. Soneto: [ Noble sin par, ostentas tu nobleza...»] (Poesías: 29); Micaela de Silva y Collás con La flor silvestre, (Poesías: 37-39); en el caso del poema de Ángela Grassi hay muchas variantes entre el original y la versión impresa, sin que sepamos quién realizó las modificaciones: El siglo diez y nueve. Dedicado a S.M. la Reyna Doña Isabel II con motivo de su heroico desprendimiento en favor del público tesoro: [ «Lóbrega está la noche: el viento muje(sic)...»]; Joaquina García Balmaseda: A S.M. la Reina $d^{a}$ Isabel $2^{a}$ con motivo de la cesión de sus bienes al Estado. (Soneto) [«Lisonjera contigo la fortuna...! ].

26. Poesías dedicadas á S.M. la Re ina Doña Isabel II al ceder á la Nación la mayor parte de su Real Patrimonio. Madrid, Rivadeneyra, 1865, pp. 13-16. Real Biblioteca, Mss. II/ 3326.

27. Real Biblioteca, Mss II/4040 (11), 4hs con portada, autógrafo.

28. Real Biblioteca, Mss II/4040. 
INAUGURACIÓN DEL CANAL DE ISABEL II. 1858

Conocíamos la relación que en los primeros años de su carrera literaria mantuvo Faustina Sáez de Melgar con Palacio, a través de su familia política, y el mecenazgo de la Reina disponiendo que todas las escuelas públicas se suscribieran a la revista que dirigía, La Violeta. Tras la caída de Isabel II mostraría sus verdaderos intereses con su vinculación a los krausistas, si bien no dejó, al volver la monarquía, de retomar los vínculos palatinos, como demuestran algunos poemas dedicados a la infanta Paz, por ejemplo. Reproducimos un poema manuscrito, que creemos inédito: A S.M. la reina $D^{a}$ Isabel segunda en la inauguración del Canal que lleva su augusto nombre 29 :

Ved cual se agita el pueblo tumultuoso,

Lanzando por doquier plácido grito,

Ávido de admirar el portentoso

Alto caudal, que llega al infinito.

Lleno su pecho de gozoso anhelo,

Acude a contemplar en este día

Del fecundo Lozoya en nuestro suelo,

El rico manantial que nos envía.

$¡ O h$ ! Miradle correr grande y potente

Sus aguas ved a tan inmensa altura

Deslizarse, cual rápido torrente

Asegurándonos días de ventura.

Decirnos quiso el murmurar sonoro

Con melodioso y argentado acento

«Hoy te lego, Madrid, un gran tesoro

Recíbelo con himnos de contento.

Se que esta villa, pobre, entristecida

Sus campos secos, áridos, sombríos

En breve ostentarán embellecida

Rica y feliz con los caudales míos.

En breve sus magníficos pensiles

Te ofrecerán sus olorosas flores

Sonoras fuentes brotarán a miles

Con cascadas y bellos surtidores.

El industrial activo y codicioso

Recogerá mis aguas cristalinas

Y el labrador con ellas afanoso

Trasformará en edenes sus colinas.

29. Real Biblioteca, Mss II/4040 (37), 2 hs., autógrafo firmado.

Anales, 23, 2011, pp. 289-308 
El poderoso encontrará hermosura

Dulce recreo, amenidad notoria

Daré a la Ibera Corte galanura

Y a su reina inmortal, eterna gloria».

Esto el Lozoya con murmúreo blando

Dijo al brotar en ímpetu bravo,

Absorta el alma lo escuché temblando,

Y hoy lo traduce el pensamiento mio.

Bendecid Ysabel, la bondadosa,

Que os viene a dar la dicha imaginada

¡Oh! Vedla siempre grande generosa

De su España leal idolatrada.

Ved la alegría que en su frente brilla

Por el inmenso bien que os concedió

¡Gloria a la Soberana de Castilla

Que obra tan colosal patrocinio!

Himnos doquier de gratitud eleva

El pueblo, que la aclama jubiloso

Que raudo el viento por el orbe lleva

Cual emblema de paz, no glorioso.

Y cual madre la adora entusiasmado

El rico y el magnate la venera

Que hará glorioso su inmortal reinado

La escelsa nieta de Ysabel primera.

La augusta madre, su constante amor

Siempre celosa de su timbre y gloria

Recuerda amante que su nombre caro

Símbolo fue mil veces de victoria.

Y hoy asociado a la gigante empresa

A través de los siglos trasmitido

Su gloria el tiempo conservando ilesa

Será por las naciones bendecido.

\section{ONOMÁSTICAS REALES}

Uno de los temas recurrentes en la poesía femenina decimonónica fueron los versos con motivo de santos y aniversarios dirigidos a familiares, amistades o personajes por lo que, como era de esperar, Isabel II protagonizó muchos. Damos noticia de algunos, inéditos. 
Las Religiosas de S. Pascual de Aranjuez, felicitan a su Reina y Señora y a su Augusta Hija la Infanta $D^{a}$ Isabe $^{30}$.

Himnos de triunfo y gloria

Cantemos en este día

Y lo alaben a porfía

Las páginas de la Historia.

Hoy quisieramos, Señora

Ofreceros una flor

Como emblema del amor

Que nuestro pecho atesora

Por que (sic) tienen tal encanto

Aunque mudas son las flores

Que con sus bellos primores

Saben desterrar el llanto

[1v] Pero la mano de Rosa

En vano se cansaría

Nunca simbolizaría

Nuestro Cariño, Señora.

Hoy infinitos amores

Quisiéramos encontrar

Y poderos presentar

Tambien infinitas flores.

Reciba del alto Cielo

Como otro tiempo Israel

La Reina doña Isabel

Su gracia, amor y consuelo.

Y después de recibir

Nuestro amor puro y leal

Una corona inmortal

Llegue algún dia a ceñir.

(2r)Nuestro cariño reciba

La Infanta $\mathrm{D}^{\mathrm{a}}$ Isabel

Que nuestro corazón fiel

Pide al Cielo la bendiga.

De alli descienda una flor

Con gracia y belleza tanta

Que obsequie a la Augusta Infanta

Con su hermosura y primor.

Hoy la Celestial Ester

Su hermoso manto la tienda

30. Real Biblioteca, Mss II/4040 (66).

Anales, 23, 2011, pp. 289-308 
Y en lo adverso la defienda

Con su divino poder

Isabel Morante es otra autora desconocida que recurre también al recuerdo de la antepasada homónima:

A S. M. la Reina $D^{a}$ Isabel Segunda en sus días ${ }^{31}$

¿Qué vivificador astro, allá en la esfera,

Brilla hermoso, feliz y sacrosanto?

La estrella pura de Isabel primera,

Cuyo glorioso rayo, al orbe causa espanto.

La que alumbró los campos de Granada

Cuando la cruz clavase en sus almenas,

Iluminando la famosa espada

Que vencio las legiones agarenas.

La que fúlgida, grande, majestuosa,

Nube alguna jamás su brillo empaña,

La misma que en su lumbre deliciosa

Hoy derrama feliz por toda España.

La que de luz fulgente inmensa hoguera

Fuente de bienes es magna y fecunda,

Y si un tiempo siguió a Isabel primera,

hoy resplandece en Isabel segunda.

\section{VIAJES REALES}

\section{A BARCELONA}

La visita de Isabel II a Barcelona se produjo el año 1860 y dio lugar a un Álbum conmmorativo dedicado por el Ayuntamiento, cuyo manuscrito se conserva en la Real Biblioteca.

Isabel de Villamartin, gallega de nacimiento pero residente en Cataluña desde su infancia, fue una de las primeras autoras que contribuyó al renacimiento de las letras catalanas. Había obtenido en 1859 la Flor natural con su poesías a «Clemencia Isaura» en los Juegos Florales de Barcelona, y celebra aquí la visita de Isabel II a la ciudad Condal, tres años después de efectuarse, con un poema que fecha en Madrid, el 1 de Octubre de 1863 y en el que se confiesa huérfana y desvalida.

\section{A S.M. la Reyna Doña Isabel Segunda ${ }^{32}$ \\ El (sic) la bella y altiva Barcelona, \\ Te vi, Señora, por la vez primera,}

31. Real Biblioteca, Mss II/4040 (76).

32. Real Biblioteca, Mss II/4040 (89). Autógrafo firmado.

Anales, 23, 2011, pp. 289-308 
Cruzabas la carrera

Del pueblo catalán acompañada,

Y mientras te aplaudía,

Desde mi humilde esfera

Un saludo de amor te dirigí.

Yo vi irradiar en tu serena frente

De los antiguos Condes la corona,

Y el pueblo que blasona

De los hechos que brillan en su historia

Te contempló admirado,

Y aclamó con el pecho enagenado

A la regia matrona

Que así honraba las glorias del pasado! (sic)

Desde entonces fue todo mi deseo

Poder besar tu mano bienhechora

Y decirte: Señora,

Yo en la triste orfandad paso mi vida,

[1v] Que el que impera en la muerte

No reserve a tus hijos igual suerte,

Y nunca destructora

Ose el velo tocar de tu alma fuerte.

Aquella visita fue celebrada por otras autoras conocidas y que en aquellos años ya utilizaban el catalán como lengua materna. Es el caso de Victoria Peña de Amer: A S.M. la Reina $D^{a}$ Ysabel segunda con motivo de su venida á Barcelona: [ «A dónde vais, Ysabela...»] ${ }^{33}$. También participa María Josefa Massanes: A S.M. la reina en el acto de colocar la primera piedra para las obras del nuevo puerto: las marítimas glorias catalanas» [ « ¿Sabéis Matrona excelsa...»] $]^{34}$.

\section{A SEVILLA}

El año 1862 la reina visita Andalucía, y autoras andaluzas tienen un motivo para agradecérselo. La famosa entonces y respetada Antonia Díaz de Lamarque escribe: A S.M. Isabel II en su visita de Isabel II al hospital de la Santa Caridad de Sevilla, poema que formará parte de la Corona poética que ofrecen á S.M. $D^{a}$ Isabel $2^{a}$ el Ayuntamiento constitucional de Sevilla y la Real Academia de Buenas Letras [ «Cuando cien y cien pueblos alcanzaron...»] ${ }^{35}$.

Luisa López Salvador, desconocida hasta el momento, firma el 28 de octubre de 1862: A Nuestra Reyna Isabel II en el día de su marcha: [«Lo mismo,

33. Real Biblioteca, Mss VIII/M/262, f. 18r-19r. Autógrafo firmado.

34. Real Biblioteca, Mss VIII/M/ 262, fol. 95r-96v.

35. Sevilla, [Establ. Tip. de la Andalucía], 1862. 
Señora...» $]^{36}$. Se conserva el manuscrito original de Dolores Arráez de Lledó, fechado en Granada ese año de 1862 con el título: A S.M. Isabel II: [«Huid, huid, fatídicos crespones...»] $]^{37}$, que sería publicado como Himno en honor de S.M. la Reina cantado por las niñas del Hospicio a su entrada en dicho establecimiento ${ }^{38}$.

\section{A SEGOVIA}

Cuesta creer, a la vista de los siguientes versos, que fueran las herederas de Santa Teresa quienes los escribieran. Por su ingenuidad los reproducimos sin modificaciones.

Carmelitas Descalzas de Segovia ${ }^{39}$

Toda la comunidad

de Carmelitas Descalzas, se pone con humildad

a Vuestras Reales Plantas

Para agradecer mui fina

la estimada visita

de V Real Majestad

y de su amada familia.

Dios la de mucha saluz

y una vida dilatada, para poder conserbar

la Religión en España.

Bien se conoce Señora

que su grande corazon

abriga un amor ardiente

a toda la Religion,

Pues se olvida, dege (sic) el Reino

por benir a visitar

a las hijas de Teresa,

en este tosco sayal.

Y tambien a Nuestro Padre

mucho se lo agradecemos,

tenga tanta debocion,

con el sagrado Carmelo.

36. Real Biblioteca, Mss II, 3307 (6).

37. Real Biblioteca, Mss II/3307 (7).

38. Real Biblioteca, Caja foll. $\mathrm{H}^{\mathrm{a}}$ 29-7.

39. Real Biblioteca, Mss II/4040 (79).

Anales, 23, 2011, pp. 289-308 
Vien conocemos Señora!

que mui afligida esta,

mas como Reina prudente, tiene que disimular.

Para su mucho consuelo Dios la conserbe también toda su Real familia juntamente con el Rei.

Con la visita de ayer, emos quedado con gozo pero a faltado el consuelo, de ber a su amado esposo.

Pues como es Piedra mui fina el Sr. le está labrando que tenga mucha paciencia para llevar los trabajos.

Bien se conoce que es, su vida mui meritoria pues le fia los trabajos ques el precio de la gloria.

Aora deseamos saber cómo a esa ayer llegó pues el nublado tan fuerte a todas nos sorprendio.

Toda esta Comunidad en oracion seguida Pidiendo misericordia A Ntro Dios y Señor,

Por vuestra Real Majestad Y todo acompañamiento, Que tubimos el onor de Ver en nuestro conbento.

A dios señora a dios Dios nos conceda algun dia, La beamos en la gloria, Como a la Reina de Ungria.

Pues como la ymita en el nombre, También en su santidad, Pues a todos edifica, Con su mucha caridad.

Perdone señora estas letritas Y vea el amor de las carmelitas 
Pues de corazon mucho la queremos

Y con su presencia bien nos complacemos.

\section{AL PAÍS VASCO}

Peregrina del Real de Mántaras publica en 1865 unas Composiciones poéticas dirigidas á S.M. la Reina al pisar el suelo vasco y en la M.N. Villa de Tolosa, que incluyen dos poemas suyos, uno con el título del Baño del Príncipe y otro en vasco dirigido al Príncipe ${ }^{40}$.

\section{A LAS ISLAS BALEARES}

Manuela de los Herreros, natural de Palma de Mallorca, participa en la Corona poética dedicada a S.M. la Reina Doña Isabel II... con un poema que comienza: [ «Bendecid Baleares el día...» y otro tanto hace Angelina Martínez Lafuente [«Salve Reina Isabel! Flor nacarada...»] ${ }^{41}$.

\section{MOTIVACIONES LABORALES. GERTRUDIS GÓMEZ DE AVELLANEDA}

En otros lugares hemos dado cuenta de otros tipos de relaciones de autoras como Emilia Pardo Bazán o la Condesa de Mina con Isabel II ${ }^{42}$, y tan sólo añadiremos aquí la transcripción de dos cartas que completan las ya conocidas dirigidas por Gertrudis Gómez de Avellaneda al Duque de Riansares ${ }^{43}$, esposo de la Reina Madre, al que solicita entrar al servicio, ya sea de la Duquesa de Montpensier, ya de las hijas del infante don Francisco, aunque deja bien claro que preferiría ser Azafata de María Cristina. Hace patente los servicios prestados por su padre y su segundo esposo a la monarquía y la penuria económica en que se encuentra.

En las siguientes cartas, recuerda de nuevo que ha dedicado a María Cristina su Devocionario para, a continuación, poner de relieve la ingratitud de la Familia Real con ella y describe su situación con tintes patéticos. Aun así,

40. Tolosa, Tip. Laborde, 1865.

41. Corona poética dedicada a S.M. la Reina Doña Isabel II al inaugurarse el monumento que las Islas Baleares erigen en la capital de la provincia para perpetuar... la visita... en 1860, Palma, [s.n. Imp. de Pedro José Gelabert], 1863.

42. Simón Palmer, María del Carmen. «Carta inédita de Emilia Pardo Bazán a María Cristina de Habsburgo(1894)», Grial, 36(1998) 137, pp. 133-36; «Las finanzas de las escritoras románticas», en A la zaga de tu huella. Homenaje al profesor Cristóbal Cuevas, Málaga, Universidad, 2005, Tomo I, pp. 597-612.

43. Se ha actualizado la acentuación. Archivo Histórico Nacional. Borbón, María Cristina de. Reina de España. Diversos. Títulos Familias 3406, Leg. 132, Exp. 1. 
la escritora no consiguió entrar en Palacio y su testamento demuestra que al fallecer estaba muy lejos de la pobreza ${ }^{44}$.

I.

Excmo. Sor. Duque de Riansares

Muy Sor. mío y de mi consideración y aprecio: la bondad que reconocen en V. todas las personas que tienen el honor de tratarle, la necesidad en que me veo de buscar un apoyo poderoso, y el convencimiento que tengo de la benevolencia que V. concedía a mi difunto Esposo, me animan a dirijir a V. estas líneas, que pude hacer llegar a V. recomendadas por el Sor. Egaña, que no hubiera reusado (sic) este favor a la viuda de un amigo suyo; pero que me determino a enviar a $\mathrm{V}$. directamente para mayor brevedad, y porque creo que para un corazón tan noble y generoso como el de V. bastan para recomendarme mi sexo desvalido, mis desgracias, y la confianza que pongo en su protección de $\mathrm{V}$.

Mi ruego, Sor. Duque, es para [2r] que V. se sirva recomendarme a la Augusta Sra. Su Esposa, alcanzándome en primer lugar la gracia de que se digne aceptar la dedicatoria de un Devocionario que voy a publicar, y en segundo que me conceda su Real apoyo para alcanzar una plaza de Azafata cerca de S.A. la Sra. Infanta Duquesa de Montpensier, o en fin, una colocación en el servicio de las Sras. Hijas del Infante D. Francisco ya que no pueda ser, como yo desearía mas que nada, que se me destinase al servicio de la misma Reina Madre, Sra. que hallaría en mi la mayor gratitud por cualquiera de estas gracias que me viniera de su augusta mano.

El motivo de mi primera pretensión es porque teniendo resuelto no volver a escribir, bien que hasta ahora haya sido la literatura mi única distracción, he querido honrar en lo posible mis últimas [3] obras; con este objeto alcancé de SS.MM. la Reina y el Rey se dignasen aceptar la dedicatoria de dos obras poéticas, y deseo que la otra religiosa que juntamente con aquellas van a salir a luz, sea favorecida con la alta protección de la Reina Madre. El no tener editor me ha impedido publicarlas hasta ahora, pero lo haré en breve, rindiendo este leve homenaje a la Augusta y Real Familia a quien consagro mis producciones.

Respecto a mi pretensión segunda nada tengo que decir. Sabido es, Sor. Duque, los grandes gastos que me ocasionaron la enfermedad, viaje y muerte de mi marido, y mi escasa fortuna tuvo con esto tal postración que me veo necesitada para sostenerme con el decoro debido, de un destino correspondiente a mi clase de hija y esposa de altos funcionarios, lo cual jamás alcanzaré si la Reina Madre no me honra con su augusta protección que nadie mejor que $\mathrm{V}$. puede proporcionarme.

44. Simón PALmer, María del Carmen, «Lego a la tierra, de que fue formado, este mi cuerpo mortal...Últimas voluntades de Gertrudis Gómez de Avellaneda», Revista de Literatura, 62 (2001)124, pp. 525-70. 
Yo me encomiendo, pues, a su bondad de V.(4) Sor. Duque, rogándole me perdone esta libertad que me tomo, y que teniendo presente que soy una mujer sin amparo alguno en el mundo, que ha sido muy infeliz en todos conceptos, y que hasta ahora no ha obtenido gracia ninguna del Trono en servicio del cual murieron su Padre y su Esposo, me mire con benevolencia no deje burlada la confianza con que recurro a su bondad.

Soy, Sor. Duque, con los sentimientos del mayor aprecio y consideración. Su muy atenta y affma. Servidora Q.B.S.M.

Gertrudis Gómez de Avellaneda, viuda de Sabater.

Hoy 10 de noviembre.= Calle de S. Marcos num. 10, pral.

II.

Excmo. Sor. Duque de Riansares

Muy Sr. mío y de mi consideración: Me permití molestar su atención de V. avisándole había quedado vacante una plaza de Azafata, esperando de su bondad me recomendase a la Augusta Reina Madre según se sirvió ofrecerme cuando por primera vez tuve el honor de escribirle para rogarle me dispensase su poderosa protección. Hoy vuelvo a tomar la pluma, aunque sin haber tenido todavía noticia alguna de que llegase a manos de V. mi anterior, con objeto de poner en su conocimiento que el Sor. Gobernador de Palacio, Marques de Miraflores, me ha escrito diciéndome que S.M la Reina nuestra Sra. había decidido suprimir la clase de Azafatas, no proveyendo las vacantes. Este aviso me ha sorprendido pero he creído mi deber comunicarlo a V. ya que me ha permitido antes abusar de su bondad para que me hiciese propicio el ánimo de la Excelsa Sra. de cuya mano me [2] prometía una merced que la Real determinación de su Augusta Hija hace ya imposible. Esta nueva prueba de mi mala suerte no me sorprende, Señor Duque, pues tengo ya conocido lo poco que tengo que esperar del destino, y acato como debo la Real resolución, aunque no puedo menos de deplorar que siendo la única persona de mi sexo que ha cultivado las letras en España, según le permiten sus débiles fuerzas; el único escritor que ha obtenido premios literarios en calidad de Cantor de la Reina, el único que en tiempos de triste recordación ha ensalzado públicamente en sus pobres versos el nombre Escelso de la Reina Madre, hija de un militar benemérito que murió al servicio del Rey difunto; viuda de un alto funcionario que mereció la confianza del Trono, y en fin, siendo una mujer desvalida que incesantemente ha implorado la generosidad de sus Príncipes para que la atendiesen como se dignan hacerlo con todos los escritores nacionales, haya sido la única excluida constantemente de las Regias bondades, teniendo el profundo dolor de no haber merecido ningún género de apoyo o protección, ninguna leve señal de la Rl. benevolencia, sin duda por ser este mi destino [3] Tócame solamente el resignarme con esta mi adversa suerte, rogando a Dios que derrame en S.M. tantos beneficios cuantos son mis infortunios, y dando a V. las más rendidas gracias por sus buenos deseos a mi favor, y suplicándole sirva reiterar a S.M. la Reina Madre mi profunda gratitud por la honra que me dispensó de dedicarle mi última y 
religiosa producción literaria (que aún se haya en la imprenta) y que espero tener el honor de poner a sus Rles. Plantas en todo el mes próximo.

Quedo, Sor. Duque, con los sentimiento mas distinguidos, de V. atentamente y affma. servidora

Q.B.S.M= Gertrudis Gómez de Avellaneda

Hoy 27 de diciembre. Calle de San Marcos, $n^{\circ}$ 18, cto. pral.

Lo cierto es que Isabel II atendió peticiones de ayuda de escritoras, como la de Josefa Díez Carralero, «La ciega de Manzanares» a la que concedió una pensión, o la ofrecida a los hijos de Carlota Cobo, cuando ésta le dedicó la biografía novelada por ella de su madre, Agustina de Aragón. Alojó en las casas del Patio de Banderas del Alcázar de Sevilla a Fernán Caballero, etc, etc. Conviene, por último, recordar que dos de sus hijas serían años más tarde escritoras: Paz y Eulalia de Borbón.

Fecha recepción: 03/02/2010

Fecha aceptación: 07/05/2010 